\title{
Proximal femoral anatomy and collared stems in hip arthroplasty: is a single collar size sufficient?
}

\author{
Nicolas Bonin 1 , Jean-Emmanuel Gedouin², Vincent Pibarot ${ }^{3}$, Jacques Bejui-Hughues ${ }^{4}$, Hugo Bothorel ${ }^{5}$, \\ Mo Saffarini ${ }^{5^{*}}$ (1) and Cécile Batailler ${ }^{6}$
}

\begin{abstract}
Background: Even if the benefits of collars are unclear, they remain widely used, in several femoral stem designs. This study aimed to determine whether collar size should be proportional to hip dimensions and morphology. The hypothesis was that the collar should be larger for greater stem sizes and for varus femoral necks.

Methods: Computed Tomography scans of 204 healthy hips were digitally analysed and manually templated to determine principle dimensions, appropriate stem size and model, as well as cortical distance at the femoral calcar (ideal collar size).

Results: Univariable analysis revealed that cortical distance was moderately correlated with mediolateral offset $(r=0.572 ; p<0.0001)$ and stem model $(r=0.520 ; p<0.0001)$. Cortical distance was weakly correlated with head diameter $(r=0.399 ; p<0.0001)$, stem size $(r=0.200 ; p=0.017)$, and patient gender $(r=0.361 ; p<0.0001)$.

Multivariable analysis confirmed that stem model $(p<0.0001)$ and head diameter $(p=0.0162)$ are directly correlated to cortical distance.

Conclusion: We found that cortical distance along the femoral calcar is directly correlated with the model of the stem implanted ('standard' or 'varus') and with the head diameter. This cortical distance indicates optimal collar size, which would grant maximum calcar coverage without prosthetic overhang. Collar size should be proportional to the size of the operated hip, and should be larger for 'varus' stem models than for 'standard' stem models.
\end{abstract}

Keywords: Total hip arthroplasty, Collared stem, Prosthetic overhang, lliopsoas impingement, Stem subsidence, Preoperative planning

\section{Background}

The advent of uncemented Total Hip Arthroplasty (THA) required alternative implant features to grant initial stability and stimulate long-term osteo-integration. The addition of collars to femoral stems was intended to enable load transfer to the resected femoral calcar, and thereby prevent implant subsidence within the cancellous bone of the metaphysis (Demey et al., 2011; Flecher et al., 2012).

Since their development, collars have been controversial, with unclear evidence of their benefits. Several authors investigated the benefits and drawbacks of collared

\footnotetext{
* Correspondence: journals@resurg.eu

${ }^{5}$ ReSurg SA, Chemin de la Vuarpillière 35, 1260 Nyon, Switzerland Full list of author information is available at the end of the article
}

stems and found little or no differences, in either shortor long-term outcomes, when compared to collarless stems (Al-Najjim et al., 2016; Caglar et al., 2008; Ebramzadeh et al., 2004; Lenart et al., 2012; Weber et al., 2014). Conversely, a number of clinical studies supported the use of collars and argued that they could improve stem survival and facilitate revision THA (Flecher et al., 2012; Kale et al., 2000; Van Kleunen et al., 2006). Furthermore, good collar-calcar coverage could prevent stem subsidence and rotation, which may occur during the first weeks following uncemented THA (Campbell et al., 2011; Parvizi et al., 2004; Simpson et al., 2010; Strom et al., 2007; Weber et al., 2014).

The efficacy of a collar depends on how well it covers the femoral calcar (Demey et al., 2011; Fischer et al., 
1992; Jeon et al., 2011; Keaveny \& Bartel, 1993; Mandell et al., 2004). While an undersized collar may be insufficient to prevent stem subsidence or rotation (Fig. 1a and b) (Meding et al., 1997), an oversized collar may lead to painful prosthetic impingement against the ilipsoas or other soft tissues (Fig. 1c) (Brew et al., 2011; Lindner et al., 2013). To the authors' knowledge, however, there are no published studies that investigated optimal collar dimensions in relation to stem size or neck angle.

Even if its benefit remains unclear, the collar is widely used in current femoral stems. The purpose of the present study was to determine whether collar size should be proportional to the dimensions and morphology of each hip. The hypothesis was that the collar should be larger for greater stem sizes and for varus femoral necks. Such findings could help implant manufacturers adjust the dimensions of the collar as required for each implant size and standard/varus model.

\section{Methods}

The authors studied 204 Computed Tomography (CT) hip scans taken for femoral angiography at a cardiology centre in 2014. The images were all acquired using the same scanner (Philips Brilliance 64, Amsterdam, The Netherlands) with $2 \mathrm{~mm}$ slice thickness, $1 \mathrm{~mm}$ interslice distance and reconstructions in the coronal plane. All scans were viewed in standard resolution and included the pelvis and the proximal half of the femur. Patients with arthritic or orthopaedic pathologies in either of their hips were excluded $(n=1)$.

The scans were then analysed using image-processing software to convert the DICOM images to threedimensional (3D) reconstructions (Invesalius, Campinas, Brazil). The ideal resection planes for stem positioning were determined using the engineering programme Creo (Parametric Technology Corporation, Needham, MA, USA) which calculated the 3D coordinates of (i) the femoral head centre and diameter by fitting a 'sphere of best fit', (ii) the proximal diaphyseal axis, and (iii) the femoral neck axis.

The true frontal views of 204 femurs were then printed, with magnification of $115 \%$, accounting for femoral neck anteversion. This view corresponded to the plane passing through 3 points: (a) the femoral head centre, (b) the femoral distal diaphysis centre at $120 \mathrm{~mm}$ below the femoral head centre, and (c) the femoral proximal diaphysis centre $20 \mathrm{~mm}$ proximal to the superior margin of the lesser trochanter (Fig. 2). The engineering software then used the true frontal view to automatically calculate the femoral head diameter, the femoral neck angle (FNA), between the neck axis and the diaphyseal axis, and the medio-lateral femoral offset between the femoral head centre and the diaphyseal axis. A total of four surgeons (three senior and one junior) fitted these true frontal views with templates of a collared femoral stem $\left(\mathrm{Symbol}^{\circ}\right.$, Dedienne Santé, Mauguio, France) also printed with magnification of $115 \%$. The implant is delivered in ten sizes (1-10) with each available in 'standard' and 'varus' models (femoral neck angles $130^{\circ}$ and $120^{\circ}$, respectively). For each hip, the surgeons noted the size and model of the stem that best fitted the femur and maintained the native head centre, without considering the acetabulum. The Cortical Distance (C-D) was then measured using a ruler with $0.5 \mathrm{~mm}$ graduation, at the level of the collar, between the medial margin of the stem and the outer cortex of the femoral calcar (Fig. 3). The template fitting was performed twice for each hip, by two different surgeons, to enable calculation of interobserver repeatability of all variables.

\section{Statistical analysis}

Statistical analyses were performed using $\mathrm{R}$ version 3.3.2 ( $\mathrm{R}$ Foundation for Statistical Computing, Vienna, Austria). Descriptive statistics were used to summarize the data. The inter-observer agreement was good for the choice of a 'standard' or 'varus' stems (Kappa coefficient, 0.685), satisfactory for the size of the chosen stem
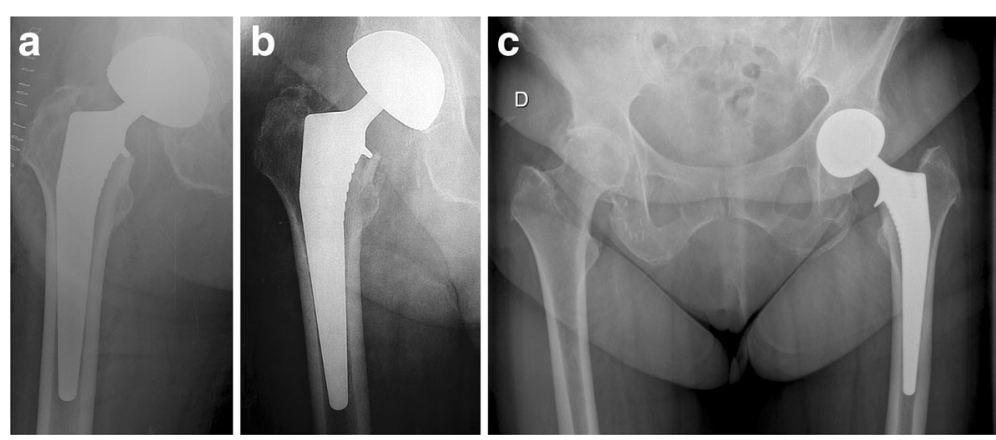

Fig. 1 a Immediate post-operative and $\mathbf{b} 2$ months post-operative X-rays of a right hip after total hip arthroplasty with insufficient collar size, showing slight subsidence with signs of calcar fracture. c Post-operative X-ray of a left hip illustrating an oversized collar, which may cause impingement on surrounding soft tissues 


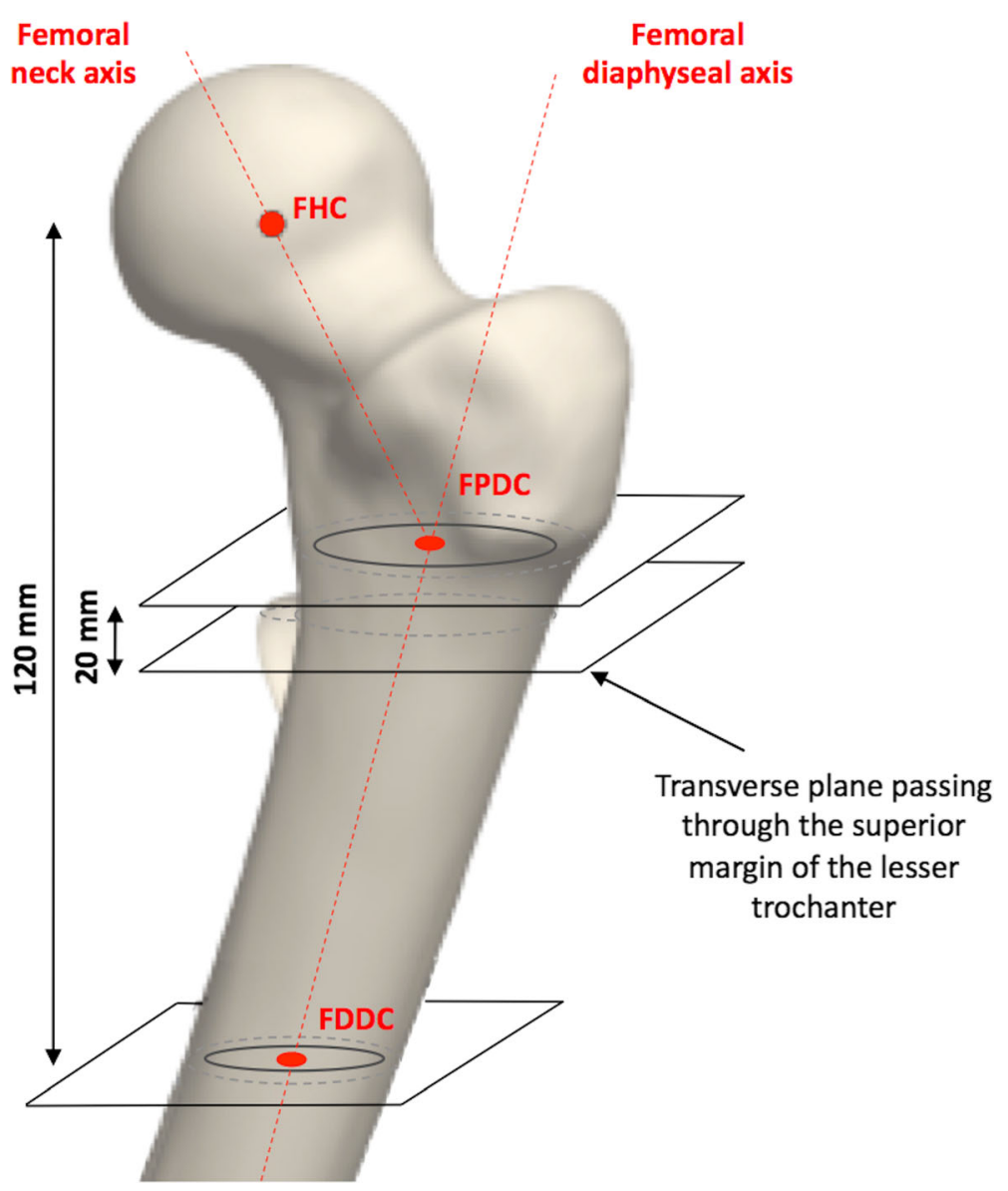

Fig. 2 Anatomic landmarks, axes and dimensions determined for each hip. The Femoral Head Center (FHC) is determined by fitting a 'sphere of best fit' to the femoral head. The Femoral Distal Diaphysis Center (FDDC) is determined by fitting an ellipse to the intramedullary cortex 120 mm below the FHC. The Femoral Proximal Diasphysis Center (FPDC) is determined by fitting an ellipse to the intramedullary cortex $20 \mathrm{~mm}$ above the superior margin of the lesser trochanter

(Kendall's tau, 0.797), and satisfactory for measurements of cortical distance (Kendall's tau, 0.642). For nonGaussian quantitative data, between group differences were evaluated using Wilcoxon rank sum tests (Mann Whitney $U$ test). For continuous variables, correlations were analysed using Pearons coefficients while for categoric variables, correlations were studied using Spearman coefficients. Step-wise descending multivariable linear and logistic regression were performed. Models assumptions were checked before the analyses were performed. $P$-values $<0.05$ were considered statistically significant.

\section{Results}

The scans studied comprised 150 male hips (73.5\%) and 54 female hips $(26.5 \%)$ aged $68.5 \pm 12.2$ years (range, 35-93 years). The mean cortical distance measured was $10.2 \pm 2.6 \mathrm{~mm}$ (range, $3.0-24.0 \mathrm{~mm}$ ). The mean FNA was $125.3^{\circ} \pm 5.7^{\circ}$ (range, $110.5^{\circ}-140.8^{\circ}$ ), and 'varus' stem models were templated for 83 of the hips (40.7\%). The selected stem size was small (1-3) for 44 hips (21.6\%), medium (4-6) for 104 hips (51\%) and large (7-10) for 56 hips (27.5\%).

There were several significant differences observed between hips of different genders (Table 1). First, men were significantly younger than women $(p<0.0001)$, and had considerably larger absolute dimensions, including cortical distance, femoral head diameter, and mediolateral offset $(p<0.0001)$. There were no significant differences, however, between men and women in terms of FNA, with equal proportions of 'varus' stems templated for both genders.

Univariable analysis revealed that the cortical distance was moderately correlated with medio-lateral offset $(r=0.572 ; p<0.0001)$, and stem model $(r=0.520$; $p<0.0001)$, as it was greater when templating 'varus' stems $(11.8 \pm 2.6 \mathrm{~mm})$ than 'standard' stems $(9.0 \pm 1.9 \mathrm{~mm})$. The cortical distance was weakly correlated with femoral head diameter $(r=0.399 ; p<0.0001)$, stem size $(r=0.200 ; p=0.017)$, and patient gender 


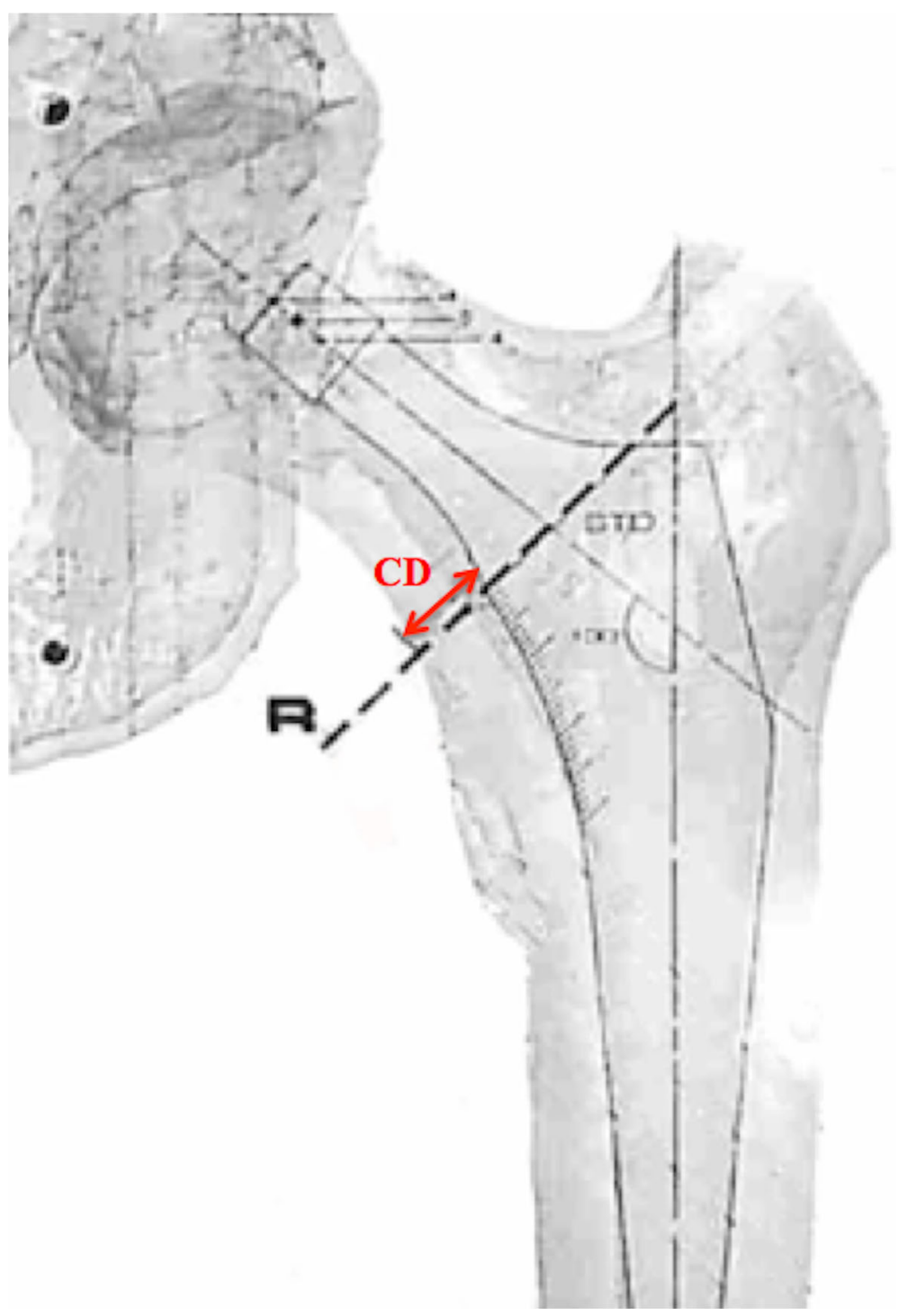

Fig. 3 Templating femoral stems on printed CT-scans to select the size and model of the stem matched and to measure the cortical distance (CD) at the level of the collar resection (femoral calcar)

Table 1 Demographics and dimensions by gender

\begin{tabular}{|c|c|c|c|c|c|c|c|c|c|c|c|c|}
\hline \multirow[b]{3}{*}{ Age } & \multirow[b]{3}{*}{ (yrs) } & \multicolumn{5}{|c|}{ Female hips $(n=54)$} & \multicolumn{5}{|c|}{ Males hips $(n=150)$} & \multirow[t]{2}{*}{$p$-value } \\
\hline & & \multirow{2}{*}{$\begin{array}{l}\text { Mean } \\
74.8\end{array}$} & \multirow{2}{*}{$\begin{array}{l} \pm \mathrm{SD} \\
\pm 12.6\end{array}$} & \multirow{2}{*}{$\begin{array}{l}\text { Median } \\
77.0\end{array}$} & \multicolumn{2}{|l|}{ Range } & \multirow{2}{*}{$\begin{array}{l}\text { Mean } \\
66.2\end{array}$} & \multirow{2}{*}{$\begin{array}{l} \pm \mathrm{SD} \\
\pm 11.2\end{array}$} & \multirow{2}{*}{$\begin{array}{l}\text { Median } \\
66.0\end{array}$} & \multicolumn{2}{|l|}{ Range } & \\
\hline & & & & & $(41.0$ & $-93.0)$ & & & & $(35.0$ & $-89.0)$ & $<0.001$ \\
\hline Femoral Head Diameter & $(\mathrm{mm})$ & 43.8 & \pm 2.4 & 44.5 & $(38.0$ & $-48.0)$ & 49.1 & \pm 2.6 & 49.0 & $(43.0$ & $-56.0)$ & $<0.001$ \\
\hline Cortical distance & $(\mathrm{mm})$ & 8.6 & \pm 2.0 & 9.0 & $(3.0$ & $-13.0)$ & 10.7 & \pm 2.6 & 10.0 & $(5.0$ & $-24.0)$ & $<0.001$ \\
\hline Medio-lateral Offset & $(\mathrm{mm})$ & 40.5 & \pm 4.3 & 39.8 & (31.3 & $-51.2)$ & 45.3 & \pm 5.1 & 45.1 & $(32.7$ & $-65.0)$ & $<0.001$ \\
\hline Stem size & $(1-10)$ & 3.7 & \pm 1.7 & 3.0 & $(1.0$ & $-8.0)$ & 5.7 & \pm 1.7 & 6.0 & $(2.0$ & $-9.0)$ & $<0.001$ \\
\hline Femoral Neck Angle & (deg) & 126.2 & \pm 5.8 & 125.9 & $(112.3$ & $-136.4)$ & 124.9 & \pm 5.6 & 124.8 & $(110.5$ & $-140.8)$ & 0.165 \\
\hline Varus Stem Model & & $40.7 \%$ & & & & & $40.7 \%$ & & & & & \\
\hline
\end{tabular}


$(r=0.361 ; p<0.0001)$. It is worth noting that significant associations $(p<0.0001)$ were also found between stem size with both mediolateral offset and femoral head diameter. Furthermore, the mediolateral offset was significantly $(p<0.0001)$ higher in hips templated with varus stems $(47.7 \pm 4.5 \mathrm{~mm})$ than with standard stems $(41.5 \pm 4.2 \mathrm{~mm})$.

Multivariable analysis confirmed that stem model $(p<0.0001)$ and femoral head diameter $(p=0.0162)$ are directly correlated to cortical distance. The FNA was neither directly $(p=0.5962)$ nor indirectly $(r=0.000$; $p=0.9288$ ) correlated to cortical distance (Table 2).

\section{Discussion}

The principal findings of the present study were that the cortical distance along the resected femoral calcar is directly correlated with the model of the stem implanted ('standard' or 'varus') and with the diameter of the femoral head. This cortical distance indicates optimal collar size, which would grant maximum coverage of the femoral calcar, without prosthetic overhang. Our data therefore suggest that collar size should be proportional to the size of the operated hip, and that it should be larger for 'varus' stem models than for 'standard' stem models. Assimilating dimensions from commercial brochures of different implant manufacturers reveals that only few of them adjust the collar size to the model and size of their femoral stems (Table 3).

Numerous studies investigated the benefits and drawbacks of collared stems and found little differences compared to collarless stems (Al-Najjim et al., 2016; Caglar et al., 2008; Ebramzadeh et al., 2004; Lenart et al., 2012; Weber et al., 2014). Other clinical studies encourage the use of collars because it may improve stem survival and simplify revision THA (Flecher et al., 2012; Kale et al.,
2000; Van Kleunen et al., 2006). Finite element analyses suggested that collars improve the distribution of axial loads on the femoral calcar and reduce tensile and rotational stresses within the cancellous bone, and thereby reduce risks of fracture and thigh pain (Fischer et al., 1992; Jeon et al., 2011; Whiteside et al., 1988). In case of insufficient support of an uncemented stem within the metaphysis, good collar-calcar coverage could prevent implant subsidence and rotation, and therefore secure its ideal position and osteo-integration. Collarless stems typically subside by 0.5 to $1.5 \mathrm{~mm}$ within the first few weeks following THA (Campbell et al., 2011; Parvizi et al., 2004; Simpson et al., 2010; Strom et al., 2007; Weber et al., 2014), which could be limited using collared stems that can withstand twice as much load (Demey et al., 2011; Whiteside et al., 1988). It remains unclear, however, whether collars tend to decrease or increase calcar resorption, as the bone remodelling process depends on multiple factors related to load transfer along the stem surface (Carlsson et al., 1995; Gibbons et al., 2001; Kadar et al., 2011; Sharif \& Parker, 2002).

Several authors support that collar efficacy depends on its coverage over the femoral calcar (Demey et al., 2011; Fischer et al., 1992; Jeon et al., 2011; Keaveny \& Bartel, 1993; Mandell et al., 2004). Kelley et al.(1993) reported that 4.6 years following THA, $47 \%$ of patients had good collar-calcar contact, none of which needed revision. On one hand, an undersized collar may be insufficient to prevent stem subsidence or rotation (Fig. 1a and b). Several stems have relatively small collars that do not reach the medial margin of the femoral calcar and thus bear only on the cancellous bone. In a series of 103 hips implanted with collared stems, Meding et al. (1997) reported insufficient coverage of the femoral calcar by the prosthetic collar in $61 \%$ of their patients. On the other

Table 2 Linear regression analysis of variables associated with Cortical Distance

\begin{tabular}{|c|c|c|c|c|c|c|c|}
\hline \multirow[t]{2}{*}{ Variable } & \multicolumn{4}{|l|}{ Univariable } & \multicolumn{3}{|l|}{ Multivariable } \\
\hline & regression coefficient & 95\% C.I. & & $p$-value & regression coefficient & 95\% C.I. & $p$-value \\
\hline \multicolumn{8}{|l|}{ Continuous } \\
\hline Age (years) & -0.04 & $(-1.27$ & $--0.22)$ & 0.006 & -0.02 & $(-0.04-0.00)$ & 0.093 \\
\hline Medio-lateral offset & 0.28 & $(1.76$ & $-2.63)$ & $<0.001$ & 0.04 & $(-0.04-0.11)$ & 0.352 \\
\hline Femoral head diameter & 0.30 & $(1.03$ & $-1.98)$ & $<0.001$ & 0.14 & $(0.03-0.26)$ & 0.016 \\
\hline Femoral Neck Angle & 0.00 & $(-0.46$ & $-0.51)$ & 0.929 & 0.01 & $(-0.03-0.06)$ & 0.596 \\
\hline \multicolumn{8}{|l|}{ Catagoric } \\
\hline \multicolumn{8}{|l|}{ Stem size } \\
\hline Small (1-3) & REF & & & & REF & & \\
\hline Medium (4-6) & 0.82 & $(-0.08$ & $-1.73)$ & 0.075 & 0.39 & $(-0.374-1.15)$ & 0.317 \\
\hline Large (7-10) & 1.48 & $(0.47$ & $-2.50)$ & 0.004 & 0.93 & $(-0.031-1.88)$ & 0.058 \\
\hline Varus stem model & 2.74 & $(2.12$ & $-3.37)$ & $<0.001$ & 2.42 & $(1.71-3.14)$ & $<0.001$ \\
\hline Male Gender & 2.11 & $(-2.87$ & $--1.35)$ & $<0.001$ & 0.68 & $(-1.574-0.21)$ & 0.132 \\
\hline
\end{tabular}


Table 3 Design characteristics of uncemented collared femoral stems by different manufacturers

\begin{tabular}{|c|c|c|c|c|c|c|}
\hline \multirow[t]{2}{*}{ Manufacturer } & \multirow[t]{2}{*}{$\begin{array}{l}\text { Stem } \\
\text { Brand }\end{array}$} & \multicolumn{2}{|c|}{$\begin{array}{l}\text { Femoral neck } \\
\text { angle }\left(^{\circ}\right)\end{array}$} & \multirow[t]{2}{*}{$\begin{array}{l}\text { Stem } \\
\text { Size }\end{array}$} & \multicolumn{2}{|c|}{ Collar Size (mm) } \\
\hline & & 'Standard' & 'Varus' & & 'Standard' & 'Varus' \\
\hline \multirow[t]{5}{*}{ Depuy } & Corail & 135 & 125 & $8-10$ & 6 & 7.5 \\
\hline & & & & 11 & 7 & 8 \\
\hline & & & & $12-14$ & 7 & 9.5 \\
\hline & & & & 15 & 7 & 11 \\
\hline & & & & $16-20$ & 8 & 12 \\
\hline \multirow{2}{*}{$\begin{array}{l}\text { Smith and } \\
\text { Nephew }\end{array}$} & Echelon & 131 & - & $11-19$ & 7.5 & - \\
\hline & Synergy & 131 & - & $9-17$ & 7.5 & - \\
\hline \multirow[t]{3}{*}{ Tornier } & Meije & 130 & 123 & $1-3$ & 7 & 7 \\
\hline & & & & $4-6$ & 8 & 8 \\
\hline & & & & $7-10$ & 9 & 9 \\
\hline Serf & Hype & 130 & - & $1-11^{a}$ & $5-7.5$ & - \\
\hline \multirow[t]{5}{*}{ Dedienne } & Symbol & 130 & 120 & $1-2$ & 6.5 & 8 \\
\hline & & & & $3-4$ & 7.5 & 9 \\
\hline & & & & $5-6$ & 8.5 & 10 \\
\hline & & & & $7-8$ & 9.5 & 11 \\
\hline & & & & $9-10$ & 10.5 & 12 \\
\hline Xnov & Cineos & 135 & 125 & $9-20$ & 7 & 7 \\
\hline
\end{tabular}

${ }^{a}$ collar size increases by increments of $0.25 \mathrm{~mm}$ for each stem size

hand, an oversized collar could, however, lead to painful ilipsoas impingement against the prosthetic overhang (Fig. 1c). In a case report, Brew et al. (2011) confirmed that, because of a large protruding collar, their patient had iliopsoas tendonitis and required revision surgery. In another case report, Linder et al. (2013) found that iliopsoas tenotomy relieved similar symptoms.

The findings of the present study revealed two interesting trends. The first trend is that cortical distance was correlated to stem size in univariable regression but not in multivariable regression. This is likely because our multivariable model included femoral head diameter, which is more intrinsically correlated with cortical distance, than is the choice of stem size per se. As noted earlier in the results, stem size is most correlated with femoral head diameter, and is thus indirectly correlated to cortical distance. Yet when hesitating between two consecutive stem sizes for the same hip, implanting the smaller stem would fill less volume in the femoral metaphysis and leave a greater cortical distance to be covered by the collar. Conversely, implanting the larger stem would fill more volume and therefore leave a smaller cortical distance to be covered by the collar. The second trend is that, while the choice of 'standard' or 'varus' stem is significantly correlated to cortical distance, in both univariable and multivariable analyses, the FNA is neither directly nor indirectly correlated to collar size. This paradoxical finding could be because the choice of 'standard' or 'varus' stems is not necessarily dependent on the native FNA, but rather on the restoration of medio-lateral offset, limb length and potential acetabular anomalies. It is worth noting that, in the present study, the authors templated the hips with the sole goal of restoring the centre of rotation of the hip, without much consideration to the acetabulum.

The main strengths of this study are its relatively large sample size (204 hips) and the accurate acquisition of CT-scans in a true frontal view. This study has several limitations related to the population studied and measurement protocol. First, hip templating was performed using one THA stem model, and it is not clear whether our conclusions apply for other commercially available femoral stems. Second, we analysed the dimensions in healthy hips, which do not represent the morphologic characteristics and sizing challenges in arthritic hips. This choice was intended to enable accurate and repeatable calculation of the centre and the diameter of the femoral head without artefacts due to arthritic or congenital deformities. Third, the population studied is predominantly Caucasian white, and may not be representative of other ethnicities. Fourth, the choices of stem size, position and model were made without considering the native acetabulum, which could influence the results. The authors assumed that the head centre corresponds to the articular centre of the hip, which in the authors' experience is a valid approximation for healthy hips (Schofer et al., 2010). Finally, the method used to measure the cortical distance had an accuracy of $0.5 \mathrm{~mm}$, which may be insufficient considering the small dimensions concerned.

\section{Conclusions}

The present study revealed that femoral cortical distance is correlated to stem model and size. Our findings could help implant manufacturers improve the designs of their existing collared stems to optimise load transfer and prevent iliopsoas impingement. Even if the benefits of collars remain unclear, optimising coverage of the femoral calcar requires adapting collar dimension to patient size and morphology.

\section{Abbreviations \\ C-D: Cortical Distance; CT: Computed Tomography; FNA: femoral neck angle; THA: Total Hip Arthroplasty}

\section{Acknowledgements}

The authors are grateful to Mr. Ryan J. Reynolds for his assistance with literature review and manuscript finalization. 


\section{Funding}

Mr. Saffarini and Mr. Bothorel received fees via ReSurg SA (Switzerland), from Dedienne Santé (France) for statistical analysis and manuscript preparation.

\section{Authors' contributions}

NB study design, data collection, literature review and manuscript writing JEG study design and manuscript editing. VB study design, data collection. JBH study design, data collection. HB literature review, statistical analysis and manuscript writing. MS literature review, statistical analysis and manuscript writing. CB study design, supervision, literature review and manuscript editing. All authors read and approved the final manuscript.

\section{Ethics approval and consent to participate}

Given that the study was performed using pre-existing CT scans, approval of the institutional review board was not required.

\section{Consent for publication}

Consent to publish was obtained from participant to include individual patient x-rays.

\section{Competing interests}

Dr. Bonin, Dr. Gedouin, Dr. Pibarot, and Dr. Bejui-Hughues received Royalties from Dedienne Santé (France) for support in study design and manuscript preparation.

\section{Publisher's Note}

Springer Nature remains neutral with regard to jurisdictional claims in published maps and institutional affiliations.

\section{Author details}

${ }^{1}$ Lyon Ortho Clinic, 29B Avenue des sources, Lyon, France. ${ }^{2}$ Nouvelles Cliniques Nantaises - Le Confluent, 3 rue Tabarly, Nantes, France. ${ }^{3}$ Service de chirurgie orthopédique et traumatologique, Hôpital Edouard Herriot, Lyon, France. ${ }^{4}$ Istituto Chirurgico Ortopedico Traumatologico ICOT, Latina, Italy. ${ }^{5}$ ReSurg SA, Chemin de la Vuarpillière 35, 1260 Nyon, Switzerland. ${ }^{6}$ Hospices Civils de Lyon, Lyon, France.

Received: 26 July 2017 Accepted: 27 September 2017

Published online: 03 October 2017

\section{References}

Al-Najjim M, Khattak U, Sim J, Chambers I (2016) Differences in subsidence rate between alternative designs of a commonly used uncemented femoral stem. J Orthop 13(4):322-326

Brew CJ, Stockley I, Grainger AJ, Stone MH (2011) Iliopsoas tendonitis caused by overhang of a collared femoral prosthesis. J Arthroplast 26(3):504 e517-509

Caglar O, Atilla B, Tokgozoglu M, Alpaslan M (2008) The effect of collar on aseptic loosening and proximal femoral bone resorption in hybrid total hip arthroplasty. Orthopedics 31(3):227

Campbell D, Mercer G, Nilsson KG, Wells V, Field JR, Callary SA (2011) Early migration characteristics of a hydroxyapatite-coated femoral stem: an RSA study. Int Orthop 35(4):483-488

Carlsson AS, Rydberg J, Onnerfalt R (1995) A large collar increases neck resorption in total hip replacement. 204 hips evaluated during 5 years. Acta Orthop Scand 66(4):339-342

Demey G, Fary C, Lustig S, Neyret P, si Selmi T (2011) Does a collar improve the immediate stability of uncemented femoral hip stems in total hip arthroplasty? A bilateral comparative cadaver study. J Arthroplast 26(8):1549-1555

Ebramzadeh E, Sangiorgio SN, Longjohn DB, Buhari CF, Dorr LD (2004) Initial stability of cemented femoral stems as a function of surface finish, collar, and stem size. J Bone Joint Surg Am 86-a(1):106-115

Fischer KJ, Carter DR, Maloney WJ (1992) In vitro study of initial stability of a conical collared femoral component. J Arthroplast 7(Suppl):389-395

Flecher X, Blanc G, Sainsous B, Parratte S, Argenson JN (2012) A customised collared polished stem may reduce the complication rate of impaction grafting in revision hip surgery: a 12-year follow-up study. J Bone Joint Surg Br 94(5):609-614

Gibbons CE, Davies AJ, Amis AA, Olearnik H, Parker BC, Scott JE (2001) Periprosthetic bone mineral density changes with femoral components of differing design philosophy. Int Orthop 25(2):89-92
Jeon I, Bae JY, Park JH, Yoon TR, Todo M, Mawatari M, Hotokebuchi T (2011) The biomechanical effect of the collar of a femoral stem on total hip arthroplasty. Comput Methods Biomech Biomed Engin 14(1):103-112

Kadar T, Hallan G, Aamodt A, Indrekvam K, Badawy M, Havelin LI, Stokke T, Haugan K, Espehaug B, Furnes $O$ (2011) A randomized study on migration of the Spectron EF and the Charnley flanged 40 cemented femoral components using radiostereometric analysis at 2 years. Acta Orthop 82(5):538-544

Kale AA, Della Valle CJ, Frankel VH, Stuchin SA, Zuckerman JD, Di Cesare PE (2000) Hip arthroplasty with a collared straight cobalt-chrome femoral stem using second-generation cementing technique: a 10-year-average follow-up study. J Arthroplast 15(2):187-193

Keaveny TM, Bartel DL (1993) Effects of porous coating, with and without collar support, on early relative motion for a cementless hip prosthesis. J Biomech 26(12):1355-1368

Kelley SS, Fitzgerald RH Jr, Rand JA, Ilstrup DM (1993) A prospective randomized study of a collar versus a collarless femoral prosthesis. Clin Orthop Relat Res 294:114-122

Lenart BA, Sherman SL, Mall NA, Gochanour E, Twigg SL, Nicholson GP (2012) Arthroscopic repair for posterior shoulder instability. Arthroscopy 28(10):1337-1343

Lindner D, Stake CE, El Bitar YF, Jackson TJ, Domb BG (2013) Endoscopic iliopsoas tenotomy for iliopsoas impingement on a collared femoral prosthesis. Arthrosc Tech 2(3):e205-e208

Mandell JA, Carter DR, Goodman SB, Schurman DJ, Beaupre GS (2004) A conicalcollared intramedullary stem can improve stress transfer and limit micromotion. Clin Biomech (Bristol, Avon) 19(7):695-703

Meding JB, Ritter MA, Keating EM, Faris PM (1997) Comparison of collared and collarless femoral components in primary uncemented total hip arthroplasty. J Arthroplast 12(3):273-280

Parvizi J, Keisu KS, Hozack WJ, Sharkey PF, Rothman RH (2004) Primary total hip arthroplasty with an uncemented femoral component: a long-term study of the Taperloc stem. J Arthroplast 19(2):151-156

Schofer MD, Pressel T, Heyse TJ, Schmitt J, Boudriot U (2010) Radiological determination of the anatomic hip centre from pelvic landmarks. Acta Orthop Belg 76(4):479-485

Sharif KM, Parker MJ (2002) Austin Moore hemiarthroplasty: technical aspects and their effects on outcome, in patients with fractures of the neck of femur. Injury 33(5):419-422

Simpson DJ, Kendrick BJ, Hughes M, Glyn-Jones S, Gill HS, Rushforth GF, Murray DW (2010) The migration patterns of two versions of the Furlong cementless femoral stem: a randomised, controlled trial using radiostereometric analysis. J Bone Joint Surg Br 92(10):1356-1362

Strom H, Nilsson O, Milbrink J, Mallmin H, Larsson S (2007) The effect of early weight bearing on migration pattern of the uncemented CLS stem in total hip arthroplasty. J Arthroplast 22(8):1122-1129

Van Kleunen JP, Anbari KK, Vu D, Garino JP (2006) Impaction allografting for massive femoral defects in revision hip arthroplasty using collared textured stems. J Arthroplast 21(3):362-371

Weber E, Sundberg M, Flivik G (2014) Design modifications of the uncemented Furlong hip stem result in minor early subsidence but do not affect further stability: a randomized controlled RSA study with 5-year follow-up. Acta Orthop 85(6):556-561

Whiteside LA, Amador D, Russell K (1988) The effects of the collar on total hip femoral component subsidence. Clin Orthop Relat Res 231:120-126

\section{Submit your manuscript to a SpringerOpen ${ }^{\circ}$ journal and benefit from:}

- Convenient online submission

- Rigorous peer review

- Open access: articles freely available online

- High visibility within the field

Retaining the copyright to your article

Submit your next manuscript at $>$ springeropen.com 